\title{
Impact of the Covid-19 Pandemic on the Mental Health of Older Adults: Charting a Road to Recovery
}

\author{
Viba Pavan Kumar
}

Received: 29 November 2021 / Accepted: 29 November 2021/Published online: 23 December 2021

(C) The Author(s), under exclusive licence to Springer Nature India Private Limited 2021

The Covid-19 pandemic has etched itself into our memories as a disaster that shook the very ground on which we stood- a disaster that led to losses of every possible type. The impact of the pandemic has been evident in every aspect of life, be it at the level of socio-economic and political spheres or the more individual-centric level of health and wellbeing. The disaster-lifecycle is a circular process that begins with mitigation, leading to preparedness, response, and recovery, and circling back to mitigation (Warfield, undated blog). As the whole world tentatively emerges from this global pandemic, there seems to have been a disruption to the usual 'disaster life cycle', with most countries having skipped to the stages of restoration and recovery without having navigated the initial stages. This holds true for clinical services including mental health services. There has been no precedence for such severe interruption in service provision in recent memory, thus not much information is available on how to breathe life back into these much needed, life-sustaining services.

Although COVID-19 is a physical health crisis, the United Nations recognised early on that it had the potential of precipitating a major mental health crisis,

V. Pavan Kumar ( $₫)$

Lead Psychologist for Older Adult Mental Health (Dudley

\& Walsall), Black Country Healthcare NHS Partnership

Trust, Dudley, UK

e-mail: viba.pavankumar@nhs.net especially for specific populations such as older adults [6]. Mental health has been a focus from the very onset of the pandemic- the sheer volume of loss, the trauma of covid survivors (especially those who were hospitalised or worse still, intubated), the sudden awareness of ageing and fear of mortality, forced social isolation, and induced helplessness, seemed to provide a fertile ground for precipitating prolonged periods of stress and anxiety with the threat of these transitory emotional states evolving into more enduring mental illness for all sections of the society, but more so for those deemed vulnerable.

There is evidence trickling in that the impact of the pandemic on individuals was influenced, amongst other factors such as financial status and race, by their pre-existing health and health inequalities. Not surprisingly, those affected more adversely during the pandemic included those with disabilities and older adults. Whilst children kept busy with home-schooling and adults of working age learned to work creatively in safer ways, it was these groups that were hardest hit.

Older Adults as a group became a more 'at risk' group due to not only their age, but also due to associated frailty and comorbid physical health conditions that made them susceptible to lowered immunity and risk of infection. Enforced isolation due to being identified as extremely vulnerable, reduced access to face-to-face medical care or social care due to social-distancing rules led to the suspension of several services creating greater levels of need in this 
group that was largely unmet; prolonged periods of being home-bound or in some cases bed-bound were associated with complications such as reduced mobility, malnutrition, the risk of developing both physical health and mental health comorbidities, and being at risk of neglect. Those with pre-existing mental illnesses were more at risk for relapses and exacerbations in presentations. In the absence of adequate and timely monitoring or treatment, those living with families saw an associated increase in significant carer stress, which posed an added layer of complexity that called for urgent attention which, if unaddressed, has been reported to lead to the risk of an increase in incidence of abuse and hospitalisation or institutionalisation.

The pre-pandemic line of thought was that older adults, in general, had lower stress reactivity, and had better emotional regulation and well-being than younger adults [4], but given the scale and magnitude of the pandemic, there has been an increasing concern about a mental health crisis among older adults. Initial studies that aimed to capture the mental health of older adults during the pandemic seemed promising as there were no reports of significant increase in depression, anxiety, or substance misuse [7], but these studies were mainly online surveys conducted in the communities of developed nations, that relied on subjective reports by those who had access to technology that facilitated participation in the studies; they did not take into consideration those who may have conditions associated with negative health outcomes (such as those with lower incomes, mental health problems, dementia, those caring for someone with dementia, or having chronic physical health conditions or those living in assisted facilities). It remains to be seen what the long-term outcome of Covid-19 has been on the mental health of those deemed vulnerable.

More recently, there have been a few published reports on the negative impact of the Covid-19 pandemic in older adults in the community, those under secondary mental health teams, and those admitted to in-patient settings. In the general community, overall wellbeing, activity levels, and sleep were reported to be affected along with associated changes in cognitive functioning [2]. Those under the care of secondary mental health services were forced to rely on remote care that posed challenges for both the service users and clinicians [5] and were at times deemed sub-optimal. The key challenges in in-patient settings, besides containing the risk of transmission, was to deal with the impact of shielding patients from visitors/family on the patients' wellbeing and to deal with the new demands of end-of-life planning.

The last 18 months have posed challenges like none before- how does one instil hope, which is the basic prerequisite in the recovery journey, when there is doom and gloom all around? How do we build resilience in the community as a part of the 'mitigation' stage of the disaster- lifecycle? How can we ensure that the 'response' stage of cycle factors in the gaps in care introduced due to the disruptions to services? How do we implement care-plans that rely on daily monitoring or high-intensity interventions when there are palpable shortages in staffing levels and financial resources? In hospital-settings, how can equitable and inclusive access to care be ensured irrespective of the age of the service user?

Lessons learnt from earlier pandemics like SARS have proved that regular telephonic contact, healthy monitoring by and contact with family, relevant and updated information, caring for the general medical and psychological needs, and respecting their personal space and dignity are important components of mental health care in the elderly [10]. This warrants sensitization at all levels for early detection of mental health care needs and plan appropriate interventions, especially for the vulnerable older adult population irrespective of the locus of their residence.

When the system around us is falling apart, it seemed that one of the ways to ensure some semblance of continuity of care was for clinicians to rely on themselves to take on roles which may well be outside their professional remit. This would then invariably add to the risk profile of not only the service users but also to the health and wellbeing of the individual clinicians. A whole other battle that is emerging is the impact of the pandemic on health-professionals' wellbeing [9]. Vacancies and staffing shortages, difficulties in coping with ever-changing Covid-safe working guidelines, the challenges of containing the risk of infection, and depleted emotional and financial resources are threatening health-care systems and risk becoming a pandemic of a different sort. 
Recovery in mental health in general is a non-linear concept, a far cry from the definition of 'absence of symptoms' which is oft used in the medical world, but in the field of Older Adult Mental Health it carries the risk of becoming a far-fetched goal unless we begin charting out a new trajectory and start to redefine the word, especially in these unprecedented times. Research thus far has focused on utilising subjective reports in surveys that may not best capture the true extent of the varied impact the pandemic has had on the older adult cohorts. Outcome measures of personal recovery like the Recovery Star (Donna, n.d.) or the Recovery Assessment Scale [1] offer a multi-faceted approach to understanding recovery but fall short in factoring the impact of the pandemic on overall wellbeing. Capturing the current levels of need or Quality of Life in vulnerable groups like older adults or those with acquired degenerative conditions in the light of gaps in service provision due to the pandemic has become a challenge as there are no templates to elicit this information.

Whilst well researched pathways of care may help chart the restoration and recovery journeys of individuals or even groups of individuals with specific conditions, there is an urgent need to build an evidence base for optimal models in recovery of service provisions which is equitable, accessible, and fit for purpose. The individual recovery relies heavily not only on individual, person-cantered factors but also on extrinsic systemic factors such as fine-tuning services that exist, and/or setting up of tailor-made services where there is a paucity. Now more than ever is a need for research that would systematically explore the impact of the pandemic in these marginalised groups and test innovative interventions that aim to bridge the gaps created by the pandemic.

As services especially those catering to older adults wade through murky waters, there has never been a greater need in long-term health care sectors for competent and decisive clinical leadership by those with a vision, who would help provide road-maps to move out of the pandemic-induced maze of obstacles.

\section{References}

1. Corrigan PW, Giffort D, Rashid F, Leary M, Okeke I. Recovery as a psychological construct. Community Ment Health J. 1999;35(3):231-9. https://doi.org/10.1023/a: 1018741302682.

2. De Pue S, Gillebert C, Dierckx E, Vanderhasselt M-A, De Raedt R, Van den Bussche E. The impact of the COVID-19 pandemic on wellbeing and cognitive functioning of older adults. Sci Rep. 2021;11(1):4636. https://doi.org/10.1038/ s41598-021-84127-7.

3. Donna. (n.d.). Recovery $\operatorname{Star}^{\mathrm{TM}}$ (4th Edition)-Triangle. Https://Www.Outcomesstar.Org.Uk/. Retrieved 12 November 2021, from https://www.outcomesstar.org.uk/ using-the-star/see-the-stars/recovery-star-4/

4. Lee EE, Depp C, Palmer BW, Glorioso D, Daly R, Liu J, Tu XM, Kim H-C, Tarr P, Yamada Y, Jeste DV. High prevalence and adverse health effects of loneliness in communitydwelling adults across the lifespan: role of wisdom as a protective factor. Int Psychogeriatr. 2019;31(10):1447-62. https://doi.org/10.1017/S1041610218002120.

5. Liberati E, Richards N, Parker J, Willars J, Scott D, Boydell N, Pinfold V, Martin G, Dixon-Woods M, Jones P. Remote care for mental health: Qualitative study with service users, carers and staff during the COVID-19 pandemic. BMJ Open. 2021;11(4): e049210. https://doi.org/10.1136/ bmjopen-2021-049210.

6. United Nations. (2020). Policy brief: COVID-19 and the need for action on mental health. United Nations. https:// unsdg.un.org/resources/policy-brief-covid-19-and-needaction-mental-health

7. Vahia IV, Jeste DV, Reynolds CF. Older adults and the mental health effects of COVID-19. JAMA. 2020; 324(22):2253-4. https://doi.org/10.1001/jama.2020.21753.

8. Warfield, C. (undated blog). The Disaster Management Cycle. Retrieved 12 November 2021, from https://www. gdrc.org/uem/disasters/1-dm_cycle.html

9. Wilson, C. (2020). Mental health impacts of COVID-19 on NHS healthcare staff. https://post.parliament.uk/mentalhealth-impacts-of-covid-19-on-nhs-healthcare-staff/

10. Wu P, Fang Y, Guan Z, Fan B, Kong J, Yao Z, Liu X, Fuller CJ, Susser E, Lu J, Hoven CW. The psychological impact of the SARS epidemic on hospital employees in China: exposure, risk perception, and altruistic acceptance of risk. Can J Psychiatry Revue Canadienne De Psychiatrie. 2009;54(5):302-11. https://doi.org/10.1177/07067437090 5400504 .

Publisher's Note Springer Nature remains neutral with regard to jurisdictional claims in published maps and institutional affiliations. 